\title{
Elemental and biochemical nutrient limitation of zooplankton: a meta-analysis
}

\author{
Patrick Thomas ${ }^{1}$, Charlotte Kunze ${ }^{1}$, Dedmer Van de Waal ${ }^{2}$, Helmut Hillebrand ${ }^{1}$, and \\ Maren Striebel ${ }^{1}$ \\ ${ }^{1}$ University of Oldenburg \\ ${ }^{2}$ Netherlands Institute of Ecology
}

March 10, 2022

\begin{abstract}
Primary consumers in aquatic ecosystems are frequently limited by the quality of their food, often expressed as phytoplankton elemental and biochemical composition. Effects of these food quality indicators vary across studies, and the relative importance of elemental (nitrogen and phosphorus) versus biochemical (fatty acid and sterol) limitation in aquatic food webs has been debated. Here we present results of a meta-analysis using $>100$ experimental studies, which confirms that limitation by $\mathrm{N}$, $\mathrm{P}$, essential fatty acids, and sterols all have significant negative effects on zooplankton performance. However, effects varied by grazer response (growth versus reproduction), specific manipulation, and across taxa. P limitation had greater effects on zooplankton growth than fatty acids, but $\mathrm{P}$ and fatty acid limitation had equal effects on reproduction. Furthermore, we show that nutrient co-limitation in zooplankton occurs, that indirect effects induced by P limitation exceed direct effects of mineral $\mathrm{P}$ limitation, that effects of nutrient amendments using laboratory phytoplankton isolates exceed those using natural field communities, and that algal physiology mediates zooplankton responses to nutrient limitation. Our meta-analysis reconciles contrasting views about the role of various food quality indicators, and their interactions, for zooplankton performance, and provides a mechanistic understanding of how environmental change affects trophic transfer.
\end{abstract}

\section{Hosted file}

Thomas_et_al_Food_quality_March_1_2022_preprint.pdf available at https://authorea.com/users/ 463562/articles/558617-elemental-and-biochemical-nutrient-limitation-of-zooplankton-ameta-analysis 